INTERNATIONAL DESIGN CONFERENCE - DESIGN 2018

https://doi.org/10.21278/idc.2018.0238

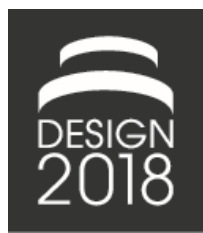

\title{
INTEGRATING INDIVIDUAL KNOWLEDGE INTO INNOVATION PROCESSES OF R\&D ALLIANCES
}

\author{
Y. Canik, N. Fain, E. Bohemia, I. Telalbasic and V. Tewes
}

\begin{abstract}
Innovation processes involve individuals from different disciplines within and across organisations, who exchange knowledge to undertake tasks. Exchanged knowledge is tacit in nature and, for an organisational benefit, it needs to be integrated into innovation processes. To achieve this, this paper proposes a conceptual framework based on the literature, suggesting a circle of retrieving, creating, validating, codifying, storing, communicating and coaching new individual knowledge mitigated by boundary objects including design artefacts from the case of innovation processes of R\&D alliances.
\end{abstract}

Keywords: knowledge sharing, design tools, open innovation

\section{Introduction}

Innovation processes involve contributions from individuals undertaking various functions (e.g. design, engineering, marketing, finance) within and across organisations (Mahr et al., 2014; Grigoriou and Rothaermel, 2017). Throughout these processes, they exchange knowledge to innovate and solve problems (Arnett and Wittmann, 2014). The exchanged knowledge consists of explicit and tacit knowledge (Nonaka and Takeuchi, 1995; Lam, 1997; Chua, 2002; Cavusgil et al., 2003; Seidler-de Alwis and Hartmann, 2008). It is the tacit knowledge which is difficult to codify because it is hidden within the actions, commitments, values, emotions, educational background, natural talent and experiences of individuals (Nonaka and Takeuchi, 1995; Koskinen and Vanharanta, 2002; Kikoski and Kikoski, 2004; Seidler-de Alwis and Hartmann, 2008). This paper explores how individual tacit knowledge, can be integrated into innovation processes through 'boundary objects' (e.g. databases, reports, models) including 'design artefacts' (e.g. drawings, prototypes) to benefit future innovation processes within and across organisations.

It is widely acknowledged that tacit knowledge is relevant in undertaking tasks and solving problems throughout innovation processes because the opinions of individuals provide creative solutions (Kikoski and Kikoski, 2004; Seidler-de Alwis and Hartmann, 2008; Arnett and Wittmann, 2014). Organisations, however, can only benefit from tacit knowledge, if they have a structured approach towards integrating it into their innovation systems so that they can benefit from it for the future processes (Kikoski and Kikoski, 2004; Seidler-de Alwis and Hartmann, 2008; Zhang et al., 2013; Tsai and Hsu, 2014). However, this is challenging (Nonaka, 1994; Cavusgil et al., 2003) because, collaboration processes varying among individuals within and across organisations (Bartel and Garud, 2009) lead to the following pre-existing knowledge boundaries: syntactic (lack of knowledge share), semantic (lack of knowledge translation) and pragmatic (lack of interest to share knowledge) (Carlile, 2004).

It has been suggested that two key activities can facilitate integration of individual knowledge into innovation processes: (i) crossing pre-existing knowledge boundaries (Carlile, 2004) and (ii) learning from new individual knowledge by absorbing it into organisational systems (Lyles and Salk, 1996; Kale 
et al., 2001; Carlile and Rebentisch, 2003; Tsai and Hsu, 2014). To mitigate this process of knowledge integration, the literature proposes 'boundary objects' (Bucciarelli, 2002; Carlile, 2002; Carlile, 2004; Jalonen, 2011) and design studies suggest the significance of 'design artefacts' that are considered types of boundary objects (Bertelsen, 2000). Although boundary objects including design artefacts are widely acknowledged in the literature, the little discussion is provided on how they mitigate the innovation processes (Bertelsen, 2000). Therefore, there is a need to address this gap (Alegre et al., 2013).

Across the boundaries of a single organisation, strategic Research \& Development (R\&D) alliances, in particular, have challenges in mitigating the innovation processes for individual knowledge integration (Grigoriou and Rothaermel, 2017). To begin, within these alliances, the management of knowledge needs to happen within and beyond a single organisation (Noseleit and de Faria, 2013) as organisations build R\&D alliances through collaboration and co-operation for the purposes of achieving greater innovation results than it could have done individually (Han et al., 1998; Ahuja and Katila, 2001; Koschatzky, 2001; Sáez et al., 2002; Sampson, 2005; Liao et al., 2007; Keil et al., 2008; Lin et al., 2012). Moreover, the knowledge boundaries in such alliances are even more complex, as the network of collaborating individuals, who need to integrate their individual knowledge into the innovation process, increases (Sampson, 2007). Furthermore, R\&D alliances, have challenges in coordinating the innovative activities because of challenges regarding integrating individual knowledge into their innovation processes, but the literature regarding this area currently provides little evidence (Grigoriou and Rothaermel, 2017). Therefore, there is a need for new studies focusing on how innovation activities can be mitigated to integrate individual knowledge (Alegre et al., 2013).

This paper addresses this gap by building a theoretical proposition to explore how boundary objects including design artefacts mitigate individual knowledge integration throughout innovation processes of R\&D alliances. To develop the proposition, the literature focusing on individual knowledge, knowledge integration, innovation processes of $\mathrm{R} \& \mathrm{D}$ alliances, boundary objects including design artefacts is reviewed. The conceptual framework is presented as an outcome of the review and a short validity and reliability test for it is outlined. The paper concludes with key limitations to the approach and future steps.

\section{Literature review}

\subsection{Individual knowledge in innovation processes}

Knowledge is an important resource for organisations to undertake tasks, propose new solutions to problems, learn from processes or situations and make decisions (Nonaka, 1994; De Long and Fahey, 2000; Liao et al., 2007; Alegre et al., 2013). Individual knowledge, in particular, plays a key role in delivering successful innovation processes and solving problems based on the subjective opinions and expertise of individuals (Cavusgil et al., 2003; Kikoski and Kikoski, 2004; Seidler-de Alwis and Hartmann, 2008; Arnett and Wittmann, 2014).

Individual knowledge has a level of explicitness and tacitness (Nonaka and Takeuchi, 1995; Lam, 1997; Chua, 2002; Cavusgil et al., 2003; Seidler-de Alwis and Hartmann, 2008; Arnett and Wittmann, 2014). Unlike explicit knowledge that is easy to codify and verbalise, tacit knowledge leads to aforementioned boundaries inhibiting communication (Nonaka and Takeuchi, 1995; Koskinen and Vanharanta, 2002; Kikoski and Kikoski, 2004; Seidler-de Alwis and Hartmann, 2008). It is even more difficult to integrate it into a process or structure it in a logical way (Nonaka and Takeuchi, 1995; Sampson, 2007) because it is linked to know-how, which is embedded in routines and beliefs based on subjective and intuitive opinions (Nonaka and Takeuchi, 1995). Still, individual knowledge, tacit in nature, is only significant if it can be integrated into structured organisational systems, so that integrated knowledge can be used repeatedly within organisations (Kikoski and Kikoski, 2004; Seidler-de Alwis and Hartmann, 2008; Zhang et al., 2013).

\subsection{Integrating individual knowledge into innovation processes}

Individual knowledge integration can be linked with two key processes (Lyles and Salk, 1996; Tsai and Hsu, 2014). These are: (1) crossing boundaries through creating and validating new individual 
knowledge (Carlile, 2004), and (2) learning from new individual knowledge by absorbing it into organisational systems (Kale et al., 2001; Carlile and Rebentisch, 2003; Tsai and Hsu, 2014).

\subsubsection{Crossing boundaries}

Individual knowledge has different levels of tacitness, which leads to three types of pre-existing knowledge boundaries (Carlile, 2002, 2004). These are 'syntactic' boundaries that knowledge is almost explicit but not shared among individuals; 'semantic' boundaries that there are some levels of tacitness and some meanings are missing; and 'pragmatic' boundaries that knowledge is almost tacit and there is no interest to share it (Shannon and Weaver, 1949; Carlile, 2004).

To cross the 'syntactic', 'semantic' and 'pragmatic' boundaries respectively, the work of Carlile (2004) suggests an 'integrative framework' of 'transferring', 'translating', and 'transforming' individual knowledge (Figure 1). To begin, the syntactic boundaries (lack of share) can be crossed by transferring knowledge from one individual to another (Carlile, 2004), such as sending a project proposal report to R\&D partners through an e-mail. Furthermore, semantic boundaries (lack of translation) might be overcome by translating knowledge between individuals undertaking different functions (e.g. finance, sales, marketing) (Carlile, 2004) (e.g. engineers translating their work on CAD documents into PowerPoint presentation so that marketing \& sales representatives can use the knowledge engineers generate for the projects). Lastly, pragmatic boundaries (no interest to share individual knowledge) can be handled through knowledge transformation (Carlile, 2004), such as conducting workshops among $R \& D$ partners to understand their objectives and create a common interest for the project.

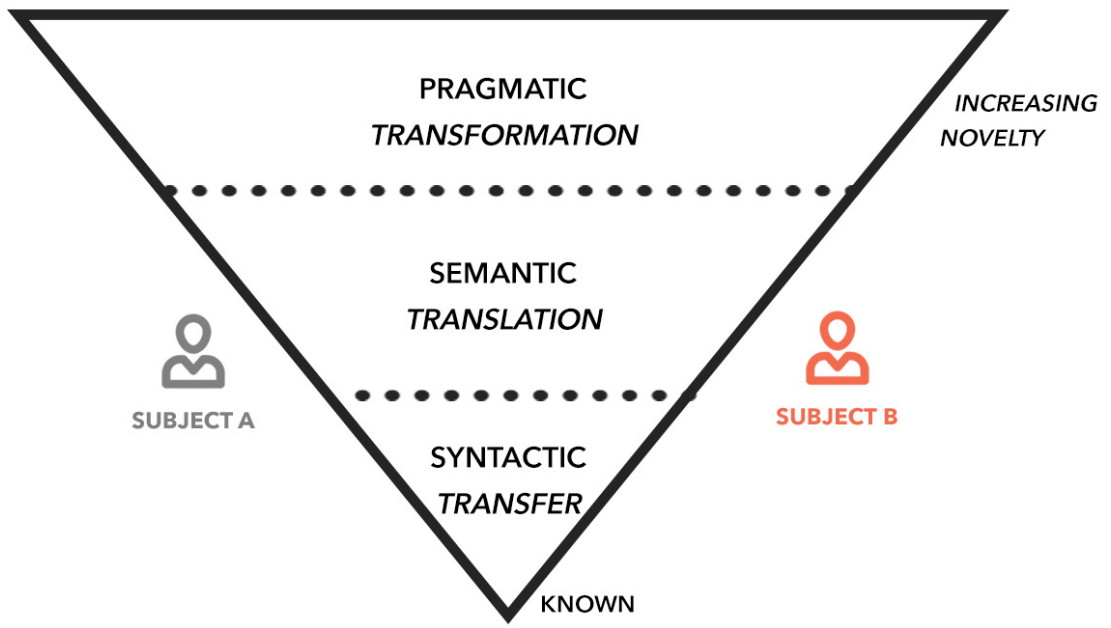

Figure 1. Types of boundaries and boundary capabilities (source: Carlile, 2004)

Carlile (2002) highlights that crossing pragmatic boundaries is the most challenging one among all boundaries, because knowledge is highly tacit and individuals undertaking different practices have no interest to adopt new knowledge. Therefore, Carlile (2002) proposes knowledge transformation steps to cross these boundaries:

- create new individual knowledge by altering existing individual knowledge

- validating/assessing new individual knowledge within and across the functions

Although the steps above are suggested for pragmatic boundaries, they can be used for crossing syntactic and semantic boundaries. As long as individual knowledge has some level of tacitness, it would need to be validated or assessed before organisations learn from it. After crossing knowledge boundaries, the second step of knowledge integration focuses on learning from new individual knowledge through organisational learning theories. 


\subsubsection{Learning from new individual knowledge}

Learning from new knowledge within a single organisation that is a partner of R\&D alliance can occur in two ways: internal and external learning (Alegre et al., 2013). Internal learning refers to learning new knowledge proposed by employees of a single organisation throughout innovation processes; external learning is that absorbing new individual knowledge proposed by R\&D partners of a single organisation (Alegre et al., 2013).

Regarding internal learning, the previous section already highlighted the need for creating and validating new individual knowledge to cross aforementioned knowledge boundaries (Carlile, 1997, 2004). As a second step, a single organisation needs to learn from validated new individual knowledge by codifying and sharing it across different functions of the organisation, which will make new individual knowledge explicit for everyone (Tsai and Hsu, 2014). Moreover, after creating, validating, codifying and sharing new knowledge, it needs to be stored to be used for the future innovation processes (Carlile and Rebentisch, 2003).

For external learning, the work of Kale et al. (2001) suggests 4Cs of learning and leveraging know-how of alliances, which focuses on the learning from tacit nature of individual knowledge of R\&D partners. The four Cs are: (i) capturing the experience by getting insights and feedback from partners, which is linked to retrieving previous knowledge; (ii) codifying these experiences in the form of guidelines to help project leaders undertake critical decisions in the process, such as partner assessment and selection, alliance negotiation, development of alliance contract; (iii) creating decision-making tools for validation and communicating through forums, networks, video conferencing, and chat rooms and (iv) coaching other employees to learn from new individual knowledge to spread new knowledge (Kale et al., 2001; Tsai and Hsu, 2014).

Introduced theories on learning from new knowledge (Kale et al., 2001; Carlile and Rebentisch, 2003; Tsai and Hsu, 2014) propose similar organisation learning processes no matter it is for internal or external learning. Moreover, the theory of Kale et al. (2001) overlaps with the theories of Carlile (1997, 2002 , 2004) to cross knowledge boundaries, which are introduced on this paper as a first step of knowledge integration (Kale et al., 2001). Based on the overlaps among theories, overall knowledge integration steps are created by merging theories for crossing knowledge boundaries and learning from new individual knowledge (Figure 2). These steps are:

- capturing/retrieving individual knowledge on previous experiences at the beginning of the innovation processes (Kale et al., 2001; Carlile and Rebentisch, 2003)

- creating new knowledge proposed by individuals from a single organisation and its partners (Carlile, 1997, 2004)

- validating/assessing new individual knowledge within a single organisation (Carlile, 1997, 2004)

- codifying and storing new individual knowledge into organisation systems (Kale et al., 2001; Carlile and Rebentisch, 2003; Tsai and Hsu, 2014).

- communicating and coaching all individuals within the single organisation (Kale et al., 2001; Tsai and Hsu, 2014).

INDIVIDUAL KNOWLEDGE INTEGRATION STEPS

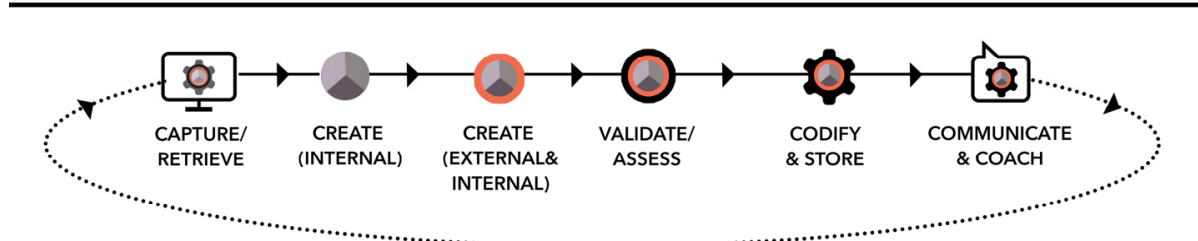

Figure 2. The steps of integrating knowledge into innovation processes

\subsection{Boundary objects including design artefacts for individual knowledge integration}

Boundary objects have subsequently been adopted by organisational and innovation studies for crossing knowledge boundaries and learning (Bucciarelli, 2002; Carlile, 2002, 2004; Jalonen, 2011), especially for collaboration activities (Star and Griesemer, 1989; Carlile, 2002, 2004; Jalonen, 2011; Nicolini et 
al., 2012). When boundary objects were first coined in social sciences, they were defined as "objects that are plastic enough to adapt to local needs and the constraints of the several parties employing them, yet robust enough to maintain a common identity across sites" (Star and Griesemer, 1989, p. 393). They enable the transformation of knowledge among individuals undertaking different functions (e.g. sales, engineering), establishing a common language among these individuals and allowing them to learn about the differences and similarities among them (Star and Griesemer, 1989; Carlile, 2002; Carlile and Rebentisch, 2003; Huybrechts et al., 2009). Star and Griesemer (1989) propose four types of boundary objects: (i) 'repositories' (modular, indexable objects) as piles of materials located in an environment that allows people to indirectly interact (e.g. museums and libraries); (ii) 'ideal types' as objects (e.g. diagrams and maps); (iii) 'coincident boundaries' which means using the same objects within a different context; (iv) standardised forms to transfer objects and communicate across parties. In addition to this classification, Carlile (2002) classifies these objects under three aforementioned knowledge boundaries: syntactic boundary objects (repositories), semantic boundary objects (forms and templates), and pragmatic boundary objects (models, objects and maps).

Among boundary objects, the study of Bertelsen (2000) and Von Hippel and Katz (2002) highlight the significance of design artefacts as boundary objects to mitigate collaborative activities. According to Bertelsen (2000), "design artefacts mitigate across heterogeneity in that they tie involved activities together, and in that they tie different rooms, phases or zones, of design and use together" (p. 19). In innovation processes, a physical scale model (prototypes), a CAD system, a file, a mailing system, annotation, marking tools, desks, walls to pin drawings can be perceived as design artefacts (Perry and Sanderson, 1998).

This paper addresses boundary objects including design artefacts as mitigating tools of individual knowledge integration steps that are illustrated on Figure 2. Common examples of these objects in innovation processes include documents, individual icons, maps, spreadsheets, workshops (Huybrechts et al., 2009), email systems, phone, documents (project proposals), built environments, visual slides (Nicolini et al., 2012), prototypes (Carlile, 2002; Bechky, 2003), IT-based artefacts such as internet applications (Levina and Vaast, 2005).

\subsection{Innovation processes of $R \& D$ alliances}

For this research, innovation involves successful creation of individual knowledge (Alegre et al., 2013) which refers to "the productive use of knowledge manifested in the successful development and introduction of new products, processes and/or services" (Dodgson et al., 2002, p. 53). This, in turn, enhances organisational innovation that is defined as implementing innovation related to products, processes and technology (Salavou et al., 2004). Based on these definitions, innovation for this research can be done in a variety of ways, through a number of knowledge integration systems, including absorption of new individual knowledge to build products, processes and transform organisations.

Among processes that are used to frame innovation activities of R\&D alliances (Van der Meer, 2007; Cooper, 2008), the current literature often discusses these activities under the umbrella of open innovation, where partners are actively contributing to the overall innovation processes for different purposes (Enkel et al., 2005, 2009; Cooper, 2008; Piller and West, 2014).

The open innovation approach enables knowledge flows among partners throughout innovation processes for monetary and non-monetary activities (Chesbrough and Bogers, 2014). Within these models, knowledge of partners can be integrated into innovation processes, internal knowledge can be leveraged and shared with partners (Gassmann and Enkel, 2004; Enkel et al., 2009; Chesbrough and Bogers, 2014). R\&D alliances participating open innovation processes work as consortia that gathers different organisations together as R\&D partners. Main R\&D partners are customers, manufacturers, universities, research institutes, government bodies, funding bodies, suppliers and competitors (Fritsch and Lukas, 2001; Sáez et al., 2002; Un and Asakawa, 2015; Canik et al., 2017). Among these partners, knowledge of customers is highly valued as a source of innovation (Sáez et al., 2002; Greer and Lei, 2012; Mahr et al., 2014; Canik et al., 2017). Regarding internal management of these projects, organisations work with employees from different functions: engineering, sales, marketing, manufacturing and operations (Olson et al., 2001; Hoegl et al., 2004;). Internal employees propose new knowledge as well as contribute to the integration of new knowledge obtained by partners into these processes (Olson et al., 2001). 
Piller and West (2014) propose a process model for open innovation clustered into four stages: i) 'defining problem', ii) 'finding participants', iii) ‘collaborating', and iv) 'leveraging'. The key activities regarding each stage are listed in Table 1.

Table 1. A process model for open innovation (source: Piller and West, 2014, p. 40)

\begin{tabular}{|l|l|}
\hline Process stage & Key activities \\
\hline Defining Problem & $\begin{array}{l}\text { Problem formulation } \\
\text { Institutions and rules: including contract terms, IP } \\
\text { Resource allocation and strategic commitment }\end{array}$ \\
\hline Finding Participant & $\begin{array}{l}\text { Identifying participants with right characteristics } \\
\text { Motivating and retaining a critical mass of } \\
\text { collaborators } \\
\text { Selecting the right participants }\end{array}$ \\
\hline Collaborating & $\begin{array}{l}\text { Governance of the collaboration process: organising, } \\
\text { monitoring, policing } \\
\text { Interaction platform and other tools } \\
\text { Openness of firm attitudes, structure and processes }\end{array}$ \\
\hline Leveraging & $\begin{array}{l}\text { Integrating external knowledge } \\
\text { Commercialising knowledge through product and } \\
\text { services }\end{array}$ \\
\hline
\end{tabular}

New individual knowledge from internal employees and R\&D partners can be integrated into each stage of open innovation process model (Table 1) through the integration steps that are outlined in Figure 2 and these steps can be mitigated by boundary objects including design artefacts. In the 'defining problem' stage, boundary objects including design artefacts, such as idea generation workshops and forums, mitigate the individual knowledge integration of gathering suggestions and complaints to formulate problems (Enkel et al., 2009; Rohrbeck et al., 2009; Piller and West, 2014). In the 'finding participants' stage, the main idea is identifying potential participants (Piller and West, 2014). A variety of boundary objects including design artefacts mitigate these processes through events and online platforms to understand whether potential R\&D partners are interested in being part of the projects (Rohrbeck et al., 2009). These two stages are different from the last two stages because partners are not part of the decision-making processes yet. In the 'collaborating' stage, R\&D partners become part of the process, so there are stronger levels of interaction, meaning there is a deeper need for organisations to learn from knowledge of their partners - often this is done through prototypes as boundary objects to undertake R\&D activities (Enkel et al., 2009; Rohrbeck et al., 2009; Piller and West, 2014). In the 'leveraging' stage, external partners from the wider networks of the alliance could be involved in the processes, such as internet platforms mitigating the innovation processes to spin-out and out-license the innovation (Enkel et al., 2009; Rohrbeck et al., 2009; Piller and West, 2014).

\section{The conceptual framework}

So far, the literature has highlighted a variety of influencing factors and potential mitigation tools to integrate individual knowledge through crossing boundaries and learning. This would consequently enhance innovation processes and future engagement of strategic R\&D alliances. A summary of the discussed constructs is presented in an integrated conceptual framework (Figure 3), which has, according to authors' understanding, not been done before. The framework builds on the literature through identifying where individual knowledge integration is needed into the innovation process of $R \& D$ alliances and provides the initial identification of where boundary objects including design artefacts may play a key role.

The framework (Figure 3) follows the open innovation stage process of Piller and West (2014). In each stage, employees from a single organisation and R\&D partners exchange knowledge that is tacit in nature (Mahr et al., 2014; Grigoriou and Rothaermel, 2017). In between stages, decision-makers in a single organisation validate new knowledge created by employees. Within this framework, the key 
decisions are related to assessing how and if individual knowledge of partners and internal employees should be used, coded and stored and what aspects of it will progress into the next stage.

As it is illustrated on each step of Figure 3, based on literature review, the following cycle of knowledge integration steps can be mitigated through boundary objects including design artefacts:

- capturing/retrieving individual knowledge of previous experiences at the beginning of the process

- creating new knowledge proposed by individuals from a single organisation and R\&D partners

- validating/assessing new individual knowledge within decision-makers of a single organisation

- codifying and storing new individual knowledge into organisation systems if it is validated through decision-making teams

- communicating and coaching all individuals within the single organisation to absorb the knowledge into organisations systems to use it for the future project

\section{INDIVIDUAL KNOWLEDGE INTEGRATION INTO INNOVATION PROCESSES OF R\&D ALLIANCES}

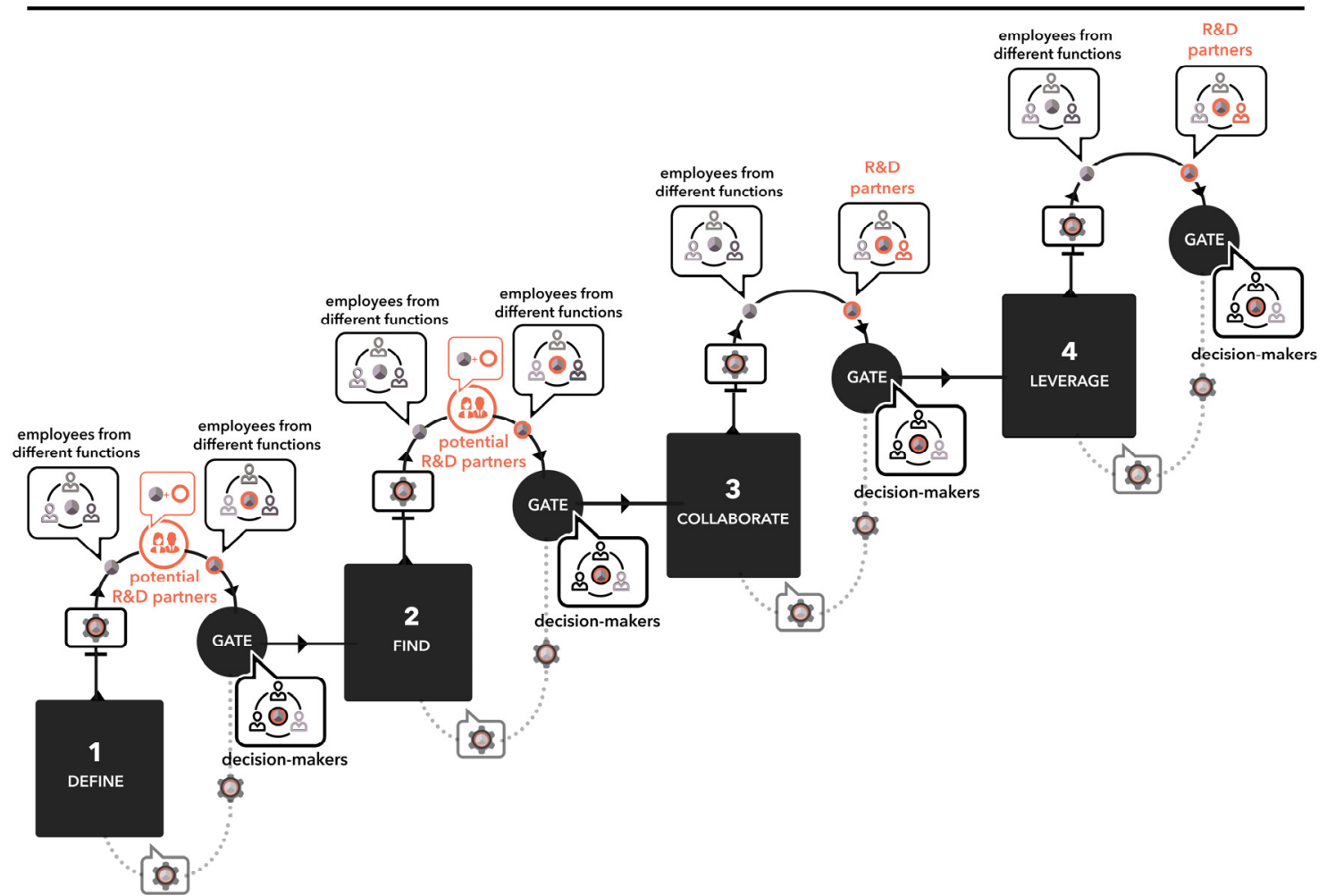

INDIVIDUAL KNOWLEDGE INTEGRATION STEPS

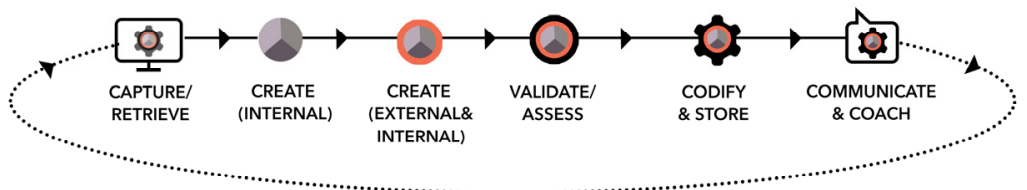

Figure 3. The conceptual framework to integrate individual knowledge through boundary objects including design artefacts

The cycle of these steps is proposed to be repeated for each stage of innovation processes, although the purpose of new individual knowledge may vary (e.g. formulating problems through workshops with potential R\&D partners on the find stage). Moreover, boundary objects including design artefacts can vary between these steps. To understand the mitigation process, this framework proposes asking questions who, what, why, how, where, whom (Hasan and Kazlauskas, 2014). 


\section{Conclusion and further steps}

The conceptual framework (Figure 3) contributes to the literature by outlining how individual knowledge is integrated into innovation processes of $R \& D$ alliances and how boundary objects including design artefacts mitigate the processes into re-usable knowledge inventory. At this stage, boundary objects including design artefacts have been cited in the literature to mitigate the knowledge integration. It is however anticipated that an exploratory study within an industrial partner will be performed in the next months to compare what is taking place within industry and whether the proposed framework is similar or different. The industrial partner is a R\&D institute specialising in the automotive industry for the manufacturing sector that researches and develops new products and services in collaboration with customers, manufacturers, universities, other research institutes and catapults.

Through a structured research protocol developed from the literature, a longitudinal ethnographic approach will be undertaken to explore individuals within the R\&D institute and its partners. Based on Figure 3, data will be collected through observations, documents, semi-structured and in-depth interviews. The observation will be done by shadowing employees and boundary objects (CzarniawskaJoerges, 2007). Semi-structured and in-depth interviews will be conducted to answer the following questions for each stage of the framework (define, find, collaborate, leverage):

- What is the key activity?

- What is the proposed new individual knowledge?

- Who proposes new individual knowledge?

- Which boundary objects including design artefacts are used to mitigate individual knowledge integration?

- How do individuals within the institute and its partner react and act towards the new individual knowledge?

- Who learns from new individual knowledge?

- What is the outcome of new knowledge within the R\&D Institute?

Using the collected data from the R\&D institute, the results will be visualised based on Figure 3. A full map of boundary objects including design artefacts will be developed which will be linked to the individuals within the innovation process.

The research outcome potentially has significant implications for design innovation and design management literature. The role of design in innovation processes has recently been divided into three sections: 'designing' (to design products, services, processes), 'design strategy' (to manage design) and (3) 'organisational design thinking' (to manage organisations) (Na et al., 2017). This research could have implications for all of these sections. From the 'designing' aspect, future studies can focus on specific boundary objects including design artefacts for innovation processes based on the research findings. Design innovation researchers will be able to review the overall map of boundary objects including design artefacts throughout innovation processes. Regarding the 'design strategy' aspect, the new studies can be developed to understand the roles of these objects and propose new objects for knowledge integration, as the research outcome would map collaborative activities mitigated by these objects. As participatory design studies propose a variety of tools for collaborative activities (Sanders, 2002; Bødker and Kyng, 2018), the findings of this research can be compared with participatory studies to propose new boundary objects including design artefacts to integrate new individual knowledge into innovation processes. For the 'organisational design thinking', further research can be conducted to investigate how these objects can be used strategically to integrate and leverage knowledge of individuals within and across organisations.

In conclusion, this research has a significant potential to contribute to the knowledge, innovation and design management literature. Still, it is at an early phase and the conceptual framework needs to be tested through further reliability and validity tests.

\section{References}

Ahuja, G. and Katila, R. (2001), "Technological acquisitions and the innovation performance of acquiring firms: A longitudinal study”, Strategic Management Journal, Vol. 22 No. 3, pp. 197-220. https://doi.org/10.1002/smj.157 
Alegre, J., Sengupta, K. and Lapiedra, R. (2013), "Knowledge management and innovation performance in a hightech SMEs industry", International Small Business Journal, Vol. 31 No. 4, pp. 454-470. https://doi.org/10.1177/0266242611417472

Arnett, D.B. and Wittmann, C.M. (2014), "Improving marketing success: The role of tacit knowledge exchange between sales and marketing", Journal of Business Research, Vol. 67 No. 3, pp. 324-331. https://doi.org/10.1016/j.jbusres.2013.01.018

Bartel, C.A. and Garud, R. (2009), “The role of narratives in sustaining organizational innovation”, Organization Science, Vol. 20 No. 1, pp. 107-117. https://doi.org/10.1287/orsc.1080.0372

Bertelsen, O.W. (2000), "Design artefacts: Towards a design-oriented epistemology", Scandinavian Journal of Information Systems, Vol. 12 No. 1, pp. 12-28.

Bødker, S. and Kyng, M. (2018), "Participatory Design that Matters-Facing the Big Issues", ACM Transactions on Computer-Human Interaction (TOCHI), Vol. 25 No. 1. https://doi.org/10.1145/3152421

Bucciarelli, L.L. (2002), "Between thought and object in engineering design", Design Studies, Vol. 23 No. 3 , pp. 219-231. https://doi.org/10.1016/S0142-694X(01)00035-7

Carlile, P. (1997), Transforming knowledge in product development: Making knowledge manifest through boundary objects, PhD thesis, University of Michigan, Ann Arbor, MI.

Carlile, P.R. and Rebentisch, E.S. (2003), "Into the black box: The knowledge transformation cycle", Management Science, Vol. 49 No. 9, pp. 1180-1195. https://doi.org/10.1287/mnsc.49.9.1180.16564

Carlile, P.R. (2002), "A pragmatic view of knowledge and boundaries: Boundary objects in new product development”, Organization Science, Vol. 13 No. 4, pp. 442-455. https://doi.org/10.1287/orsc.13.4.442.2953

Carlile, P.R. (2004), "Transferring, translating, and transforming: An integrative framework for managing knowledge across boundaries", Organization Science, Vol. 15 No. 5, pp. 555-568. https://doi.org/10.1287/orsc.1040.0094

Cavusgil, S.T., Calantone, R.J. and Zhao, Y. (2003), "Tacit knowledge transfer and firm innovation capability", Journal of Business \& Industrial Marketing, Vol. $18 \quad$ No. 1 , pp. 6-21. https://doi.org/10.1108/08858620310458615

Chua, A. (2002), “Taxonomy of organisational knowledge”, Singapore Management Review, Vol. 24 No. 2, pp. 69-76.

Czarniawska-Joerges, B. (2007), Shadowing: and other techniques for doing fieldwork in modern societies, Copenhagen Business School Press DK, Malmö.

Enkel, E., Gassmann, O. and Chesbrough, H. (2009), "Open R\&D and open innovation: Exploring the phenomenon", $R \& D \quad$ Management, Vol. 39 No. 4, pp. 311-316. https://doi.org/10.1111/j.14679310.2009.00570.x

Enkel, E., Perez-Freije, J. and Gassmann, O. (2005), "Minimizing Market Risks Through Customer Integration in New Product Development: Learning from bad practice", Creativtiy and Innovation Management, Vol. 14 No. 4, pp. 425-437. https://doi.org/10.1111/j.1467-8691.2005.00362.x

Grigoriou, K. and Rothaermel, F.T. (2017), "Organizing for knowledge generation: Internal knowledge networks and the contingent effect of external knowledge sourcing”, Strategic Management Journal, Vol. 38 No. 2, pp. 395-414. https://doi.org/10.1002/smj.2489

Han, J.K., Kim, N. and Srivastava, R.K. (1998), "Market orientation and organizational performance: Is innovation a missing link?”, Journal of Marketing, Vol. 62 No. 4, pp. 30-45. https://doi.org/10.2307/1252285

Hasan, H. and Kazlauskas, A. (2014), “Activity theory: Who is doing what, why and how”, In: Hasan, H. (Ed.), Being practical with theory: A window into business research, Wollongoog, THEORI, Australia.

Huybrechts, L., Coenen, T., Laureyssens, T. and Machils, P. (2009), "Living spaces: A participatory design process model drawing on the use of boundary objects", International Reports on Socio-Informatics (IRSI), Internationales Institut für Sozio-Informatik, Vol. 6 No. 2, pp. 6-21.

Jalonen, M. (2011), "Evolution of a boundary object through experimental learning in a networked environment", The International Conference on Organizational Learning, Knowledge and Capabilities (OLKC), Hull, UK.

Kale, P., Dyer, J. and Singh, H. (2001), "Value creation and success in strategic alliances: Alliancing skills and the role of alliance structure and systems", European Management Journal, Vol. 19 No. 5, pp. 463-471. https://doi.org/10.1016/S0263-2373(01)00062-7

Keil, T., Maula, M., Schildt, H. and Zahra, S.A. (2008), "The effect of governance modes and relatedness of external business development activities on innovative performance", Strategic Management Journal, Vol. 29 No. 8, pp. 895-907. https://doi.org/10.1002/smj.672

Kikoski, C.K. and Kikoski, J.F. (2004), The inquiring organization: Tacit knowledge, conversation, and knowledge creation: Skills for 21st-century organizations, Greenwood Publishing Group, Westport.

Koschatzky, K. (2001), "Networks in innovation resarch and innovation policy: An introduction", In: Koschatzky K., Kulicke M. and Zenker A. (Eds.), Innovation Networks. Technology, Innovation and Policy, vol 12. Physica, Heidelberg 
Koskinen, K.U. and Vanharanta, H. (2002), "The role of tacit knowledge in innovation processes of small technology companies", Production Economics, Vol. 80 No. 1, pp. 57-64. https://doi.org/10.1016/S09255273(02)00243-8

Lam, A. (1997), "Embedded firms, embedded knowledge: Problems of collaboration and knowledge transfer in global cooperative ventures", Organization Studies, Vol. 18 No. 6, pp. 973-996. https://doi.org/10.1177/017084069701800604

Liao, S.-h., Fei, W.-C. and Chen, C.-C. (2007), "Knowledge sharing, absorptive capacity, and innovation capability: An empirical study of Taiwan's knowledge-intensive industries", Journal of Information Science, Vol. 33 No. 3, pp. 340-359. https://doi.org/10.1177/0165551506070739

Lin, C., Wu, Y.J., Chang, C., Wang, W. and Lee, C.Y. (2012), "The alliance innovation performance of R\&D alliances - the absorptive capacity perspective", Technovation, Vol. 32 No. 5, pp. 282-292. https://doi.org/10.1016/j.technovation.2012.01.004

Lyles, M.A. and Salk, J.E. (1996), "Knowledge acquisition from foreign parents in international joint ventures: An empirical examination in the Hungarian context", Journal of International Business Studies, Vol. 27 No. 5, pp. 877-903. https://doi.org/10.1057/palgrave.jibs.8490155

Mahr, D., Lievens, A. and Blazevic, V. (2014), "The value of customer cocreated knowledge during the innovation process", Journal of Product Innovation Management, Vol. 31 No. 3, pp. 599-615. https://doi.org/10.1111/jpim.12116

Na, J.H., Choi, Y. and Harrison, D. (2017), "The design innovation spectrum: An overview of design influences on innovation for manufacturing companies", International Journal of Design, Vol. 11 No. 2, pp. 13-24.

Nonaka, I. and Takeuchi, H. (1995), The knowledge-creating company, Oxford University Press, New York, Oxford.

Nonaka, I. (1994), “A dynamic theory of organizational knowledge creation”, Organization Science, Vol. 5 No. 1, pp. 14-37. https://doi.org/10.1287/orsc.5.1.14

Rohrbeck, R., Katharina, H. and Gemünden, H.G. (2009), "Opening up for competitive advantage - How Deutsche Telekom creates an open innovation ecosystem”, R\&D Management, Vol. 39 No. 4, pp. 420-430. https://doi.org/10.1111/j.1467-9310.2009.00568.x

Sampson, R.C. (2005), "Experience effects and collaborative returns in R\&D alliances", Strategic Management Journal, Vol. 26 No. 11, pp. 1009-1031. https://doi.org/10.1002/smj.483

Sampson, R.C. (2007), "R\&D alliances and firm performance: The impact of technological diversity and alliance organization on innovation", Academy of Management Journal, Vol. 50 No. 2, pp. 364-386. https://doi.org/10.5465/AMJ.2007.24634443

Sanders, E.B. (2002), "From user-centered to participatory design approaches", Design and the social sciences: Making connections, pp. 1-8.

Seidler-de Alwis, R. and Hartmann, E. (2008), "The use of tacit knowledge within innovative companies: Knowledge management in innovative enterprises", Journal of Knowledge Management, Vol. 12 No. 1, pp. 133-147. https://doi.org/10.1108/13673270810852449

Star, S.L. and Griesemer, J.R. (1989), "Institutional ecology, 'translations' and boundary objects: Amateurs and professionals in Berkeley's Museum of Vertebrate Zoology, 1907-39”, Social Studies of Science, Vol. 19 No. 3, pp. 387-420. https://doi.org/10.1177/030631289019003001

Tsai, K.H. and Hsu, T.T. (2014), "Cross-functional collaboration, competitive intensity, knowledge integration mechanisms, and new product performance: A mediated moderation model”, Industrial Marketing Management, Vol. 43 No. 2, pp. 293-303. https://doi.org/10.1016/j.indmarman.2013.08.012

Zhang, H., Shu, C., Jiang, X. and Malter, A.J. (2013), "Managing knowledge for innovation: The role of cooperation, competition, and alliance nationality", Journal of International Marketing, Vol. 18 No. 4, pp. 7494.

Yasemin Canik, PhD researcher

Loughborough University London, Institute for Design Innovation

68 Stewart Road, E15 2BB London, United Kingdom

Email: y.canik@lboro.ac.uk 